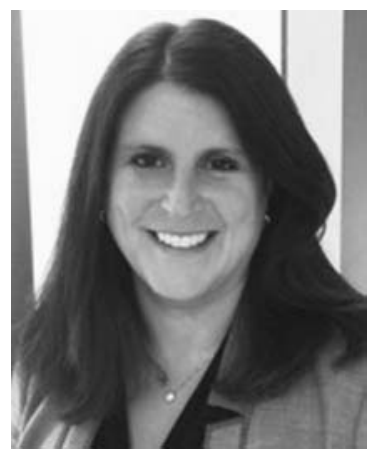

\title{
A Conversation with Karen Cichowski
}

\author{
Interviewer: Paula Kiberstis
}

Senior Editor, Science

Karen Cichowski is a Professor of Medicine at Harvard Medical School.

Paula Kiberstis: Ras is particularly important in cancer because it's highly mutated in many different cancers, particularly in the most lethal cancers. How did you become interested in ras?

Dr. Cichowski: I became interested in ras because it is one of the most commonly deregulated genes and pathways in human cancer. Not only are there ras mutations in a broad spectrum of human tumors, but you often find genetic alterations that function upstream of or downstream from ras, highlighting the importance of this pathway in the majority of cancers.

Paula Kiberstis: When mutations in the gene were discovered 35 years ago, people thought it would be relatively easy to target because it was an activated protein. That has turned out not to be the case. Can you explain why?

Dr. Cichowski: It has to do with the chemistry, although people are making strides in targeting the Ras protein itself. However, there are many other approaches that one can take to develop therapies for ras-driven cancers. That's what we've been working on in the meantime.

Paula Kiberstis: You're targeting other proteins in the pathway. What sorts of things are you doing?

Dr. Cichowski: I firmly believe that to develop a therapy for any ras-driven tumor, you have to hit part of the ras pathway. You have to either hit the RAF/MEK/ERK pathway or the PI3 K/AKT/mTOR pathway. The key is trying to identify the other drugs that you can add onto these agents to cause durable tumor regression in humans. There are several approaches one can take to achieve this.

One approach that's been very successful is to think about other types of vulnerabilities - the nononcogenic vulnerabilities - that are in a cancer cell, and try to cotarget those. For example, perhaps you could develop a therapy by targeting part of the ras pathway and then capitalizing on responses to DNA damage or oxidative stress or proteotoxic stress, for example.
Paula Kiberstis: You've tested such therapies in mouse models of cancer?

Dr. Cichowski: Yes. We always start with human cells, and we develop a hypothesis and test as many human cell lines as possible, and sometimes human xenografts. Then we test our agents in genetically engineered mouse models. The models we use have been very powerful because every animal that develops a tumor is genetically distinct; just like tumors that develop in humans, the genetics of each tumor are different. Therefore, we are able to test specific drug combinations in a large number of mice to see which of these combinations work the best and most frequently.

The most important consideration is that we're not just looking to slow tumors down. We are looking for frank tumor regression. We want the tumors to melt away. I started off developing genetically engineered mouse models to try to create animals that got cancer, and that was very rewarding, but it is much more rewarding to see a tumor shrink.

Paula Kiberstis: Mouse models sometimes get a bad rap, especially from pharmaceutical companies who take on faith that drugs that have shown efficacy in mice are going to work out in the clinic. I know you're constantly improving the models, but what's your general reaction to the frustration that you hear sometimes from the industry?

Dr. Cichowski: To develop effective therapies, we need to take a variety of approaches. People perform cellular screens in a two-dimensional culture dish. That doesn't accurately mimic a tumor in a patient, but they are still important for target identification. Xenografts are valuable because they're human cells, they are easy to use, and we can manipulate them genetically to complement drug studies. However, because cell lines are cultured indefinitely, they can genetically and epigenetically drift from the original tumor. Patient-derived xenografts are as close to the source as we can get, but they are often difficult to obtain or grow and they lack an intact immune

(C) 2016 Cichowski. This article is distributed under the terms of the Creative Commons Attribution-NonCommercial License, which permits reuse and redistribution, except for commercial purposes, provided that the original author and source are credited. 
system and microenvironment. Genetically engineered mouse models are valuable because they do have an intact immune system and tumors develop within the biologically relevant site of origin, such as the brain or the lung. The most powerful approach is to use multiple approaches.

I think that one of the reasons why drugs or specific therapies don't work in humans versus mouse models is because sometimes we're not able to dose humans in the same as we can in mouse models, often because of toxicity. Moreover, in many instances, we're not measuring pharmacodynamics in clinical trials so we don't even know if we have effectively hit the target in humans. To minimize false positives, when possible, we try to recapitulate the dosing that's used in humans. We perform extensive pharmacokinetic and pharmacodynamic studies, and then when we develop clinical trials with our clinical partners, we try to incorporate pharmacokinetics and pharmacodynamics in those human studies as well. My feeling is that, when things don't work, it's usually because the same experiment wasn't performed.

Paula Kiberstis: To get back to your combination therapies, that work has taken you into epigenetics. Tell us about that.

Dr. Cichowski: In many instances, oncogenes drive cancers; however, the ultimate transcriptional output of any oncogenic signal is likely to be determined and dictated by the epigenetic state of a cell. We're becoming more and more aware of the mutations in epigenetic regulatory enzymes. And we now know that there are mutations in both classical oncogenes, as well as in epigenetic enzymes. The question is do these defective proteins or pathways interact? And if so, how?
We noticed in several different tumor types that we would see a specific, interesting oncogenic mutation and a specific, interesting epigenetic mutation. We originally tried to cotarget these using what we thought was an "orthogonal" approach. However, in every instance where a specific drug combination works, there appears to be some nodal point of convergence. That, I think, is what's causing the vulnerability. That's what we're able to capitalize on in these combination therapies.

Paula Kiberstis: One of the drugs you're working with is a bromodomain inhibitor. How far along is that work?

Dr. Cichowski: There are bromodomain inhibitors that are in clinical trials for other indications. The hope is that they will have some clinical activity in individuals that have a very specific alteration that these inhibitors target. We're trying to develop a combination therapy now with the bromodomain inhibitors and MEK inhibitors, which works very well in our animal models. I'm very optimistic. There are many companies that have bromodomain inhibitors; now we have to see which one will be the most effective with the least toxicity. Clinical trials will determine that.

Paula Kiberstis: At Harvard Medical School you're surrounded by clinicians and near Kendall Square with all the drug companies.

Dr. Cichowski: Yes, that's quite valuable. The cancer center really makes an effort to bring in pharmaceutical companies on a regular basis so that we get that interface and that interaction, and we hear about new drugs as they're being developed. And our clinical partners are invaluable. It's that back and forth, bench-to-bedside, back-to-bench approach that has made the greatest impact. 


\section{$\$_{\text {CSH\& }}^{\infty}$ Cold Spring Harbor Symposia SYMPOSIA}

\section{A Conversation with Karen Cichowski}

Cold Spring Harb Symp Quant Biol 2016 81: 304-305 originally published online April 19, 2017 Access the most recent version at doi:10.1101/sqb.2016.81.031955

Creative This article is distributed under the terms of the

Commons http://creativecommons.org/licenses/by-nc/4.0/, which permits reuse and

License redistribution, except for commercial purposes, provided that the original author and source are credited.

Email Alerting Receive free email alerts when new articles cite this article - sign up in Service the box at the top right corner of the article or click here. 